\title{
Google Sala de Aula como interface de Aprendizagem Baseada em Problema (ABP) no Ensino Superior
}

\author{
Ivana M. Costa, Francisco N. G. Mandú, Clalber C. da Costa, Alcy F. Ribeiro, \\ Danielle C. C. Couto \\ Laboratório Interdisciplinar em Tecnologias, Educação e Computação (LITEC) - \\ Campus Universitário de Ananindeua - Universidade Federal do Pará (UFPA) \\ CEP: 67.113-901- Ananindeua - PA - Brasil \\ \{ivmirandaquim, neres.guimaraes, cclalber\}@gmail.com, \{favacho, \\ danifc\} eufpa.br
}

\begin{abstract}
In the search for methodologies to better serve the education of students of Chemistry Higher Education, one of the most promising pedagogical approaches today is Problem Based Learning (PBL). The overall objective of this paper was to plan, implement and evaluate the PBL Blended Learning approach using Google Classroom in a Higher Education class. Most participants reported that they felt more motivated and that the rotation between profiles in the BPA produced more collaborative teamwork. We conclude that a different approach to higher education and a better use of educational technologies can help teachers increase their effectiveness with a diverse student body.
\end{abstract}

Resumo. Na busca por metodologias para melhor atender à formação de estudantes do Ensino Superior da Química, uma das abordagens pedagógicas mais promissoras atualmente é Aprendizagem Baseada em Problema (ABP). $O$ objetivo geral deste trabalho foi planejar, implantar e avaliar a abordagem Blended Learning ABP utilizando o Google Sala de Aula em uma turma de Ensino Superior. A maioria dos participantes relataram que se sentiram mais motivados e que o rodizio entre os perfis na ABP produziu trabalho em equipe mais colaborativo. Concluímos que uma abordagem diferente para o ensino superior e uma melhor utilização das tecnologias educacionais podem ajudar professores a aumentar a sua eficácia com um corpo discente diversificado.

\section{INTRODUÇÃO}

Os métodos tradicionais que privilegiavam a transmissão de informações pelos professores, faziam sentido quando o acesso à informação era difícil. Hoje com a Internet e a divulgação aberta de muitos materiais, podemos aprender em qualquer lugar, a qualquer hora e com muitas pessoas diferentes [Almeida e Valente 2012].

Segundo Souza e Morales (2013), alguns componentes são fundamentais para o sucesso da aprendizagem: desafios propostos, atividades, jogos que tragam as competências necessárias para cada etapa, que solicitam informações pertinentes, que oferecem como recompensas, conquistas pessoais, que combinam percursos individuais dentro de grupos, que se inserem em plataformas educacionais, que reconhecem o aluno e ao mesmo tempo aprendem com a interação, utilizando as tecnologias. 
VIII Congresso Brasileiro de Informática na Educação (CBIE 2019)

Anais do XXV Workshop de Informática na Escola (WIE 2019)

Há atualmente uma linha tênue entre o chamado mundo físico e mundo digital, que se mescla e hibridiza constantemente. Nesse sentido a educação formal é cada vez mais blended (misturada), pois, ocorre de maneira concomitante na sala de aula e meios digitais.

Com o propósito de investigar como essas tecnologias digitais podem contribuir nas relações entre professores e alunos, bem como promover e agregar novas possibilidades aos processos de ensino-aprendizagem, fez-se necessário o presente projeto de pesquisa utilizando-se de tecnologias educacionais para identificar os fatores relevantes quanto ao uso das Tecnologias de Informação e Comunicação (TIC) como recursos de mediação pedagógica no Ensino Superior na Universidade Federal do Pará (UFPA). A UFPA oferece cursos de graduação na modalidade intensiva presencial, que são realizados em dois períodos por ano, oferecendo dois meses intensivos de aulas presenciais em campi no interior do Estado.

O objetivo geral do presente trabalho foi planejar, implantar e avaliar a abordagem Blended Learning ABP em uma modalidade que combina atividades à distância e presenciais no Ensino Superior da Química utilizando o Google Sala de Aula.

Além desta introdução, o presente artigo está dividido em mais 5 seções. A seção 2 apresenta os fundamentos sobre Blended Learning $A B P$, a seção 3 descreve os procedimentos metodológicos, a seção 4 exibe os resultados alcançados com uma turma de Ensino Superior da Química do campus Ananindeua no polo de Curuçá, e por fim, a seção 5 apresenta as conclusões.

\section{BLENDED LEARNING ABP}

Blended Learning ou Ensino Híbrido vem tomando conta dos espaços educacionais devido os grandes avanços tecnológicos da Web 2.0, o que suscita debates em torno de novas metodologias de ensino. Esse modelo de abordagem pedagógica promove misturar o ensino presencial e o ensino online buscando integrar o processo de educação junto às TICs.

O Blended Learning é, por definição, uma abordagem pedagógica que combina atividades presenciais e atividades realizadas por meio de TICs online de forma a garantir diversas abordagens o que gera um aproveitamento bastante promissor, tornando-se essencial repensar as práticas docentes e buscar metodologias para melhor atender à formação dos estudantes [Bates 2016].

Entretanto, apesar de o Blended Learning ser considerado como uma renovação ou uma ampliação de possibilidades de facilitação do processo de ensino e de aprendizagem, tem-se um período de treze anos marcados por poucos relatos de Instituições de Ensino Superior (IES) no Brasil e experiências a respeito dessa oferta de ensino o que "decorre a necessidade de que as IES afinem discussões com o MEC para que possam tomar decisões satisfatórias sobre a hibridização de seus cursos presenciais" [Zanotto et al. 2014]. 
VIII Congresso Brasileiro de Informática na Educação (CBIE 2019)

Anais do XXV Workshop de Informática na Escola (WIE 2019)

Dessa forma, dentro das propostas de Blended Learning, encontra-se a modalidade denominada Project Organized and Problem Based Learning (POPBL) ou Aprendizagem Baseada em Problemas (ABP). A primeira forma sistematizada de aprendizagem baseada em problema foi desenvolvida em 1969 por Howard Barrows e colegas na Faculdade de Medicina da Universidade McMaster no Canadá [Bates 2016].

Uma das principais características é ter o aprendiz como principal responsável pelo seu aprendizado. A aplicação do ABP contém 7 passos sequenciais: 1) Apresentar o Problema; 2) Identificar o Problema; 3) Discutir/Analisar o Problema; 4) Tentativa de Resolução/Discussão; 5) Questões/Objetivos de Aprendizado; 6) Resumir/Discutir e Pesquisar e 7) Resolução do Problema.

A ABP é aplicada em equipes de 8 a 10 alunos: composta de um mediador, um líder, um secretário e os demais componentes com funções específicas para resolução do problema. Essas funções são rotativas, além de discutir, pesquisar e solucionar os problemas propostos pelo mediador. Os meios de pesquisas são diversos, principalmente utilizando as TICs onde o papel do professor torna-se importantíssimo como facilitador, direcionando o processo de aprendizagem. Ela normalmente segue uma abordagem fortemente sistematizada para a resolução de problemas [Bates 2016].

Rikers e Bruin (2006) consideram a ABP como uma das mais proeminentes protagonistas do construtivismo. Trabalhar o ensino de química com a utilização de problemas pode contribuir para o desenvolvimento das capacidades intelectuais dos estudantes. A ABP também se caracteriza por ser uma estratégia que permite aos estudantes terem uma ação proativa na sua educação científica.

Strobel e Van Barneveld (2009 apud Bates 2016) constataram que a aprendizagem baseada em problemas é melhor para a retenção de material de longo prazo e para o desenvolvimento de competências "replicáveis", além de melhorar a atitude dos alunos em relação à aprendizagem. Os alunos desenvolvem competências em pensamento analítico e crítico pela leitura e discussão de situações complexas reais. Ademais, a aprendizagem experiencial em ambientes de aprendizagem online pode ser de dois modos: (a) aprendizagem híbrida ou invertida; ou (b) totalmente online.

A revisão da literatura retrata que houve uma significativa melhoria de aprendizado e aproveitamento dos alunos submetidos ao método ABP [Cruz e Batinga 2017; Freitas e Campos 2017; Finco-Maidame e Mesquita 2017] afirmando que ela traz benefícios decorrentes da sua capacidade para atingir objetivos educacionais mais amplos que aqueles alcançados pelas metodologias de ensino e aprendizagem convencionais, ou seja, além da construção de conhecimentos por parte dos alunos, o desenvolvimento de habilidades e atitudes que lhes serão úteis em suas futuras vidas estudantis e carreiras [Ribeiro 2010].

\section{MÉTODOS}

O modelo de abordagem pedagógica foi Blended Learning ABP misturando o ensino presencial e o ensino online, integrando o processo de educação ao uso das TIC's. Inicialmente foi realizado um amplo levantamento bibliográfico. Os resultados deste levantamento foram comparados com Schiehl e Gasparini (2017) sendo apresentados 
VIII Congresso Brasileiro de Informática na Educação (CBIE 2019)

Anais do XXV Workshop de Informática na Escola (WIE 2019)

alguns modelos existentes em buscas de Repositórios Digitais, provenientes de Mapeamento Sistemático da Literatura (MSL), por meio de alguns mecanismos de buscas acadêmicas, envolvendo artigos publicados entre os anos 2006 a 2017.

Dando continuidade à pesquisa de Schiehl e Gasparini (2017), foram considerados importantes para a pesquisa nestas bases os trabalhos a partir dos anos de 2017 até agosto de 2018. Nas fontes de pesquisas Scielo e Springer Link, somente foram considerados os trabalhos disponibilizados para consulta, ou seja, os trabalhos bloqueados foram descartados. Logo após, foram implantados os filtros de exclusão e inclusão para destacar materiais que envolvessem o uso do Blended Learning.

De acordo com o modelo de busca: ((Ensino Híbrido) OR (rotaç* por estaç*) OR (estaç*de ensino)) AND ((ensino) OR (educação) OR (aprendizagem)) e ((teaching hybrid AND blended learning) AND (model OR technique OR method*)), realizou-se um levantamento primário de 6 repositórios digitais (RDs) até o mês de agosto de 2018 , destacados na Tabela 1:

Tabela 1: Levantamento em RDs, busca por Blended Learning.

\begin{tabular}{lccc}
\multirow{2}{*}{ RDs } & $\begin{array}{c}\text { Idioma } \\
\text { Português }\end{array}$ & Inglês & $\begin{array}{c}\text { Levantamento } \\
\text { Bibliográfico }\end{array}$ \\
\hline ACM Digital Library & 44 & 11.031 & 11.075 \\
Google Acadêmico & 821 & 16.800 & 17.621 \\
Periódicos Capes & 66 & 339 & 405 \\
Science Direct & 5 & 99 & 104 \\
Scielo & 0 & 2 & 2 \\
Springer Link & 0 & 1.009 & 1.009 \\
\hline Total & 936 & 29.280 & 30.216 \\
\hline \multicolumn{4}{r}{ Fonte: RDs, pesquisa realizada até 7 de agosto de 2018. }
\end{tabular}

De acordo com Santos et al. (2017), os resultados evidenciam um crescimento bastante significativo quando o assunto é a adesão ao uso de TICs no sistema educacional. Assim, a adoção do Blended Learning com o objetivo de valorizar o aprendizado e buscar maior satisfação dos alunos coincide com as pesquisas de outros autores.

Neste levantamento constatamos que ainda são poucos os relatos e experiências de IES no Brasil a respeito dessa oferta de ensino, infelizmente corroborando com dados anteriores de Zanotto et al. (2014). A partir desta MSL selecionamos trabalhos recentes que haviam utilizado Blended Learning e ABP de maneira a comparar nossas ações e resultados, destacamos os trabalhos [Cruz e Batinga 2017; Freitas e Campos 2017; Finco-Maidame e Mesquita 2017; Rojas e Joglar 2017; Santos e Bottechia 2017].

Os participantes do projeto foram estudantes do curso de Licenciatura em Química do Núcleo Universitário de Curuçá - UFPA, matriculados na disciplina "Métodos Computacionais no Ensino de Química". No primeiro período em julho de 2018, 41 alunos responderam os primeiros formulários da pesquisa necessários para personalizar as futuras aulas presenciais e prever os recursos que seriam utilizados durante a disciplina que só ocorreu entre 28/01/2019 a 01/02/2019. 
Durante os dias 28/01 a 31/01/2019 foram ministrados conteúdos teóricos mesclando com atividades práticas no laboratório de informática, promovendo a participação ativa dos alunos durante o processo de aprendizagem.

O modelo foi constituído por aulas presenciais e ambiente virtual onde foi disponibilizado todo o material da disciplina. As aulas utilizaram projetor e um laboratório de informática com acesso à internet e a plataforma Google Sala de Aula (https://classroom.google.com), onde foram inseridos os objetos educacionais utilizados pelo professor e outros materiais como: textos, vídeos, aplicativos, exercícios, de acordo com a sequência de conteúdos estabelecida pelo PPC do Curso de Licenciatura em Química do Campus Ananindeua UFPA.

O aplicativo (app) Google Sala de Aula foi escolhido porque no levantamento dos primeiros questionários aplicados identificou-se que a maioria dos alunos tinham acesso apenas à internet móvel. Neste app o professor acompanha o estudante no desenvolvimento das atividades e, se necessário, atribui comentários e notas nas produções realizadas. E a cada nova atividade inserida, os estudantes recebem uma mensagem no e-mail, independente se o estudante compareceu as aulas presenciais e há a possibilidade de o estudante participar ativamente das atividades complementares ou de pesquisa [Schiehl e Gasparini 2016].

A metodologia do presente trabalho foi baseada no conceito de pesquisa-ação em que o plano de intervenções foi desenhado para atender aos objetivos propostos [Thiollent 2000]. O projeto compreendeu as seguintes etapas:

a) Implementação de Blended Learning ABP, utilizando um laboratório de informática.

b) Configuração do Google Sala de Aula para uma turma de Ensino Superior.

c) Avaliar o impacto do Blended Learning ABP em uma turma de Ensino Superior.

As aulas para essa turma foram ministradas mesclando momentos presenciais, conceituados como "síncrono físico" por Mateus e Orvalho (2004), onde alunos e professor estão em sala de aula ao mesmo tempo, como também através do Google Sala de Aula e a avaliação foi por meio de dois instrumentos: 1) Questionário de estratégias de motivação para aprendizagem; 2) Entrevistas Abertas realizadas junto aos alunos e professores/monitores envolvidos.

Foram formados 4 grupos, porém durante a aplicação do ABP apenas 33 alunos participaram e responderam os questionários e entrevistas finais. Após essa formação foi apresentado um Problema de Química, de maneira que os discentes buscassem a partir do uso das TICs uma solução, desta maneira as TICs foram as principais fontes de pesquisa. O laboratório de informática utilizado tinha 25 máquinas com configuração Lenovo thinkcentre core i5 8GB de RAM e $500 \mathrm{~GB}$ de HD, destas apenas 18 máquinas com internet via rádio NavegaPará de $8 \mathrm{Mbps}$.

Durante todo o período da ABP, uma professora e 3 monitores estiveram presentes de maneira a mediar o processo com os 4 grupos formados, além de realizar observações sobre $\mathrm{o}$ andamento da atividade respondendo questionários de acompanhamento dos grupos que sofreram 4 rodízios. A cada 2 horas o grupo precisava 
VIII Congresso Brasileiro de Informática na Educação (CBIE 2019)

Anais do XXV Workshop de Informática na Escola (WIE 2019)

alterar as funções dos participantes, e os mediadores precisavam anotar e conceituar a participação deles em uma função específica (líder, secretário, entre outros), além de serem entrevistados a cada troca.

O sistema de avaliação da disciplina foi dividido em dois momentos, um seminário em grupo sobre "Tecnologias Educacionais no Ensino da Química" que culminou na tarde do dia 31/01/2019 e uma atividade ABP. Nos seminários os alunos foram divididos em 6 grupos (2 grupos com 6 alunos e 4 grupos com 5 alunos).

Já para a avaliação ABP realizada dia 01/02/2019, a turma foi dividida em 4 grupos maiores (1 grupo com 9, 2 grupo com 8 e um grupo com 7 alunos). Foi explicado o sistema de rodízio dos líderes e secretários e demais membros dos grupos, além da professora houve também 3 monitores para que cada grupo tivesse um facilitador durante todo o período da atividade. Nesta atividade foram distribuídos 4 problemas distintos para cada equipe sobre Eletroquímica:

1) Corrosão de metais próximos aos manguezais;

2) Respiração celular de plantas dos manguezais;

3) Formação de placas de pirita;

4) Liberação de gases característicos dos manguezais.

As aulas presenciais ocorreram em período integral de $8 \mathrm{~h}$ às $12 \mathrm{~h}$ e de $14 \mathrm{~h}$ às 18h. Ao final do dia 01/02 foram aplicados questionários e entrevistas com alunos e professora/monitores envolvidos no projeto, a fim de compreendermos o impacto na utilização da metodologia Blended Learning ABP e o uso de TICs nesta turma de Ensino Superior.

\section{RESULTADOS}

Os resultados dos primeiros questionários de pesquisa identificaram o perfil do aluno da turma de Licenciatura em Química. Com relação ao uso do computador, apenas 40\% dos alunos da turma tinham acesso a computadores desktop ou laptop, porém verificouse que a grande maioria da turma tinha acesso à internet, destes, 77,8\% acessavam a internet por celular ou smartphones.

Desta maneira, foi necessário pesquisar softwares que pudessem ser facilmente acessados via plataforma móvel. Depois de alguns testes de desempenho e acesso em redes wi-fi limitada em velocidade selecionamos o Google Sala de Aula.

Foram elaborados planos de aulas baseados na abordagem Blended Online ABP e configurados no Google Sala de Aula. A disciplina "Métodos Computacionais no Ensino de Química" teve todo seu material didático disponibilizado via app Google Sala de Aula de maneira que os alunos tivessem acesso ao conteúdo com antecedência. Foram gerados problemas sobre Eletroquímica adaptado ao contexto da região costeira do Pará, de acordo com as características da cidade de Curuçá, rodeada por manguezais. Na figura 1 é apresentada a captura de telas do app móvel, como exemplo da visão do aluno. 
VIII Congresso Brasileiro de Informática na Educação (CBIE 2019)

Anais do XXV Workshop de Informática na Escola (WIE 2019)

Do total de alunos participantes, $94 \%$ consideraram que as técnicas utilizadas durante a realização da Blended Online ABP ajudaram no entendimento do conteúdo. Apenas $6 \%$ consideraram que ajuda foi parcial, enfatizamos que não houve nenhum resultado negativo.

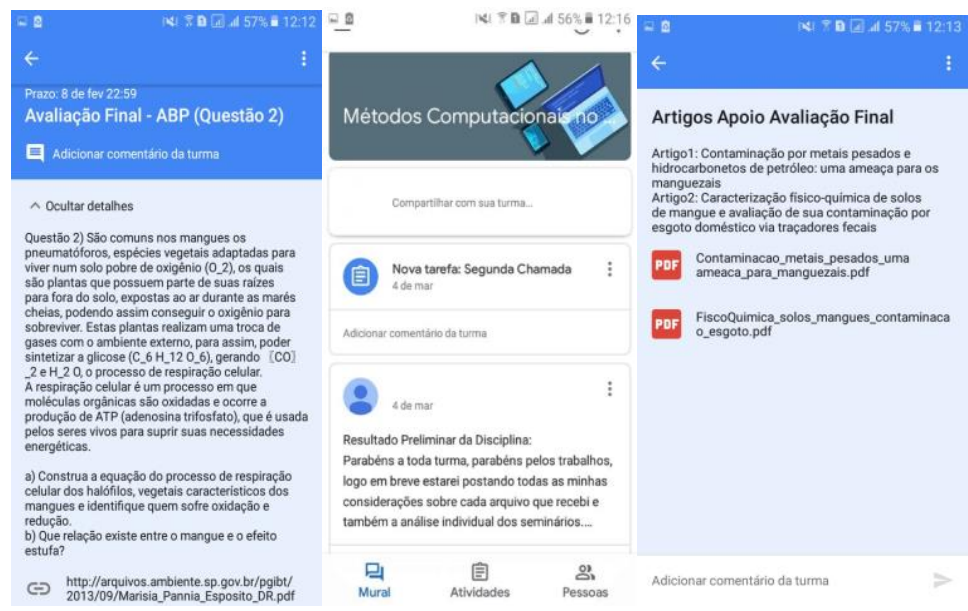

Figura 1: Screenshots do app móvel do Google Sala de Aula

Um resultado muito positivo foi a pergunta do questionário "Se os métodos de avaliação conseguiram detectar se houve aprendizado?". Do total de 33 alunos participantes, 27 alunos consideraram que sim, que os métodos de avaliação utilizados foram capazes de verificar o aprendizado, portanto criando um ambiente mais justo para avaliação destes durante a disciplina, enquanto 5 responderam que parcialmente e apenas um aluno respondeu não. A Figura 2 apresenta momentos da aplicação Blended Learning ABP com a turma de Licenciatura em Química do polo de Curuçá UFPA.

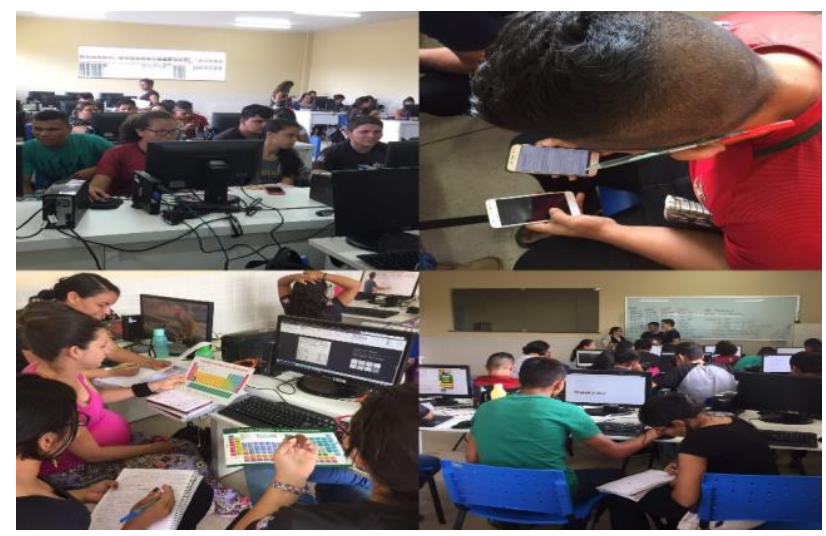

Figura 2: Blended Learning ABP utilizando o Laboratório de Informática

Outro resultado do questionário que se destacou foi a pergunta: "Você se dedicou à disciplina mais de $2 \mathrm{~h}$ por semana fora da sala de aula?". Do total, $85 \%$ dos alunos responderam sim, $12 \%$ responderam que parcialmente e apenas $3 \%$ responderam não. Algo que não ocorreu em disciplinas anteriores, relato de experiência da professora envolvida, lembrando que maior parte dos alunos anteriores consultava material complementar as vésperas das datas de avaliações. 
Quando a professora comparou os resultados dos conceitos finais da turma de 2019 onde foi aplicado o Blended Online ABP com as turmas anteriores na mesma disciplina em 2018 e 2017. Ficou evidente que o método superou suas expectativas, pois nas turmas anteriores o maior número de conceitos finais concentrava-se em REGULAR (R), enquanto na turma de 2019 o maior número de conceitos finais concentrou-se em BOM (B). Melhorando desta maneira o desempenho coletivo da turma (Figura 3).

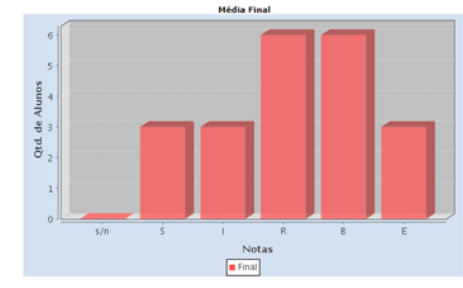

Turma de 2017

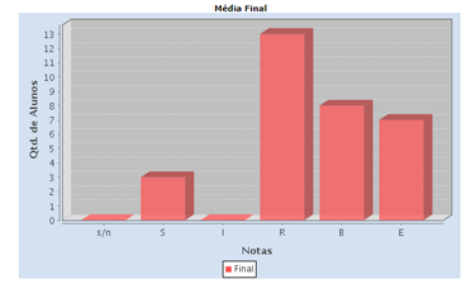

Turma de 2018

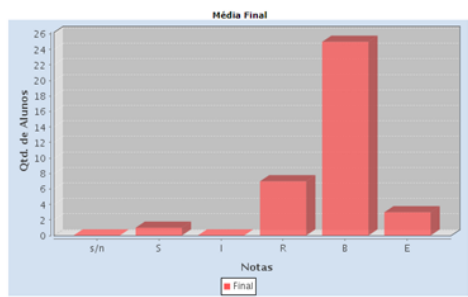

Turma de 2019

Figura 3: Estatística de notas dos alunos na disciplina "Métodos Computacionais no Ensino de Química" entre anos de 2017 a 2019 provenientes do SIGAA - UFPA (Reprovado: S/N - Sem frequência, S - Sem conceito, I - Insuficiente; Aprovado: R - Regular, B - Bom e E - Excelente)

Diversos alunos também relataram se sentir mais motivados a participar das atividades em sala de aula, por causa da ênfase prática, e que o rodízio entre os perfís da equipe na Blended Learning ABP, tiraram alguns deles de suas zonas de conforto. Alunos que nunca haviam liderado antes tiveram que assumir essa posição e alunos que estavam acostumados apenas a liderar tiveram que assumir posições de subordinação, por exemplo.

Com relação ao acesso do material de apoio, 82\% dos alunos responderam que foi fácil acessá-los, 15\% responderam que foi parcialmente e apenas 3\% afirmaram ter tido dificuldades de acesso. Dos alunos que responderam parcialmente, alguns relataram que tiveram dificuldades de acesso devido a memória dos celulares não terem mais espaço livre e devido essa questão não conseguiram fazer download de alguns materiais, outros porque não tinham plano de internet em seus celulares dependendo exclusivamente de acesso em redes wireless públicas, descartando assim problemas com o app Google Sala de Aula.

Um dos melhores resultados identificados na pesquisa foi com relação a pergunta "Se as expectativas da disciplina pelos alunos foram atendidas?", 91\% dos alunos responderam que sim e apenas $9 \%$ responderam parcialmente, destes últimos houve relatos sobre a falta de habilidades para uso das TICs, o que causou desconforto no início das atividades, porém nas entrevistas mais de $70 \%$ dos alunos afirmaram que estas dificuldades foram vencidas devido os rodízios proporcionados pelo método ABP, de tal forma, que eles tiveram oportunidade de realizar outras atividades que não estavam unicamente ligadas ao uso de TICs, inclusive fazendo rodízio de ambiente e utilizando também um Laboratório de Química.

O relato da falta de habilidade com as TICs refletiu na pergunta "Você detectou alguma dificuldade durante o andamento da disciplina?", $30 \%$ declararam que sim, sentiram dificuldade e mais 33\% sentiram dificuldade parcial, apenas $37 \%$ não sentiram dificuldade. Uma das razões identificadas foi que a maioria dos alunos não tinham acesso a computadores, e vários softwares foram usados pela primeira vez. Entretanto, destes $63 \%$ que sentiram dificuldades, 90\% conseguiu vencê-las com o apoio dos monitores e do professor que mediaram as atividades dos grupos durante a ABP. 
VIII Congresso Brasileiro de Informática na Educação (CBIE 2019)

Anais do XXV Workshop de Informática na Escola (WIE 2019)

Ao final da atividade a professora demonstrou grande satisfação com a prática, principalmente quando aplicou a ABP como última avaliação. Percebeu maior participação e interesse dos alunos durante sua disciplina comparada com turmas anteriores em que usou apenas métodos tradicionais. Também conseguiu identificar a evolução de vários alunos que iniciaram suas atividades de maneira comedida (tímidos), mas ao longo dos rodízios entre os perfis da ABP puderam demonstrar suas habilidades e todo seu esforço no envolvimento com a resolução de um problema prático, e principalmente porque o tema dos problemas propostos faziam parte do cotidiano dos alunos, eles vivenciam a realidade dos manguezais diariamente e isso gerou simpatia pelos problemas.

Os monitores também ficaram muito entusiasmados com a atividade ABP. Os alunos foram direcionados na pesquisa da resolução dos problemas e os monitores conseguiram identificar que $80 \%$ dos alunos desenvolveram competências e habilidades para solucionar os problemas de química dados durante o processo, demonstrando que a ABP tornou o processo mais dinâmico e mais envolvente para o trabalho em equipe.

\section{CONCLUSÃO}

O método Blended Learning ABP auxiliou de maneira positiva o Ensino Superior usando novas abordagens como metodologias ativas somadas as TICs. Atendeu-se a demanda da era digital no Ensino Superior de forma evolvente e dinâmica, observando a aceitação e participação dos discentes e como a ABP foi satisfatória durante o processo de ensino e aprendizagem como base no trabalho em grupo.

Ressalta-se que no Brasil estas propostas devem ser adaptadas as condições dos discentes e da infraestrutura que eles dispõem. No caso deste estudo, optou-se por explorar o Google Sala de Aula, por ser de fácil acesso em aplicativos móveis, pois a maioria dos alunos do polo de Curuçá - UFPA tinham acesso à internet a partir de celulares e smartphones.

Chegou-se a mesma conclusão de Bates (2016) sobre Blended Laerning, ou seja, esta é uma abordagem diferente para o ensino e uma melhor utilização da tecnologia para ajudar professores a aumentar a sua eficácia com um corpo discente diversificado.

Identificamos no levantamento bibliográfico um número baixo de publicações sobre Blended Learning (Ensino Híbrido) ainda na língua portuguesa, apesar do interesse cada vez mais crescente em número de publicações no mundo. Supomos que o baixo número de publicações em nossa língua, influencia o pouco desenvolvimento de Blended Learning no Ensino Básico. E a partir desta observação, desejamos adaptar o mesmo trabalho para o ensino fundamental disponibilizando material no portal do professor (http://portaldoprofessor.mec.gov.br) para que mais professores possam replicar práticas como está no Ensino da Química em nosso país.

\section{REFERENCIAS}

Almeida, M.E.B; Valente, J.A. (2012). Integração currículo e tecnologias e a produção de narrativas digitais. Currículo Sem Fronteiras, 12(3), 57-82. Disponível em: http://www.curriculosemfronteiras.org/vol12iss3articles/almeida-valente.pdf.

Acessado em agosto de 2018. 
VIII Congresso Brasileiro de Informática na Educação (CBIE 2019)

Anais do XXV Workshop de Informática na Escola (WIE 2019)

Bates, T. (2016). Educar na Era Digital: design, ensino e aprendizagem / A. W. (Tony) Bates. São Paulo: Artesanato Educacional, SP, 2016.

Cruz, M.E.B.; Batinga, V. T. S. (2017) In: Atas do XI Encontro Nacional de Pesquisa em Educação em Ciências - XI ENPEC, Universidade Federal de Santa Catarina, Florianópolis, 2017.

Finco-Maidame, G. e Mesquita, M. J. M. (2017) In: Atas do XI Encontro Nacional de Pesquisa em Educação em Ciências - XI ENPEC, Universidade Federal de Santa Catarina, Florianópolis, 2017.

Freitas, A. P.; Campos, A. F. (2017). In: Atas do XI Encontro Nacional de Pesquisa em Educação em Ciências - XI ENPEC, Universidade Federal de Santa Catarina, Florianópolis, 2017.

Mateus, A.J.F.; Orvalho, J.G. (2004). Blended-learning e aprendizagem colaborativa no ensino superior. In: VII Congresso Iberoamericano de Informática Educativa, 2004.

Ribeiro, L. R. C. (2010) Aprendizagem Baseada em Problemas PBL uma experiência no Ensino Superior. Ed. UFSCar, São Carlos, 2010.

Rikers, R. M. L. P.; Bruim, A. B. H. (2006). Adv. Health Sci. Educ. 2006, 11, 315.

Rojas, A. e Joglar, C. (2017) In: Atas do XI Encontro Nacional de Pesquisa em Educação em Ciências - XI ENPEC, Universidade Federal de Santa Catarina, Florianópolis, 2017.

Santos, M.L.C.; Bottechia, J.A.A. (2017). In: Atas do XI Encontro Nacional de Pesquisa em Educação em Ciências - XI ENPEC, Universidade Federal de Santa Catarina, Florianópolis, 2017.

Schihel, E.P.; Gasparini, I. (2017). Modelos de ensino híbrido: um mapeamento sistemático da literatura. Simpósio brasileiro de informática na educação (SBIE), Joinville, SC, v. 1, p. 1-10, 2017.

Schihel, E.P.; Gasparini, I. (2016). Contribuições do Google Sala de Aula para o Ensino Híbrido. CINTED-UFRGS, Joinville, SC, v. 14, n. 2, 2016.

Souza, C.A.; Morales, O.E.T. (2013). Mudando a Educação com Metodologias Ativas. Coleção Mídias Contemporâneas: Convergências Midiáticas, Educação e Cidadania: aproximações jovens, v. 2, p.15-33. Disponível http://www2.eca.usp.br/moran/wpcontent/uploads/2013/12/mudando_moran.pdf. Acessado em agosto de 2018.

Thiollent, M.; Araujo F.T.; Soares, R.L.S. (2000) (coord.). Metodologia e experiências em projetos de extensão. Niterói-RJ: Eduff, 2000, 340 p.

Zanotto, M.A.C; Bianchi, P.C.F.; Silva, A.P.R.; Reali, A.M.M.R. (2014). Hibridização do ensino em uma IES: delineamento de ações pedagógicas para adoção de $20 \%$ a distância em cursos de graduação presenciais. In: II Simpósio Internacional de Educação a Distância e o II Encontro de Pesquisadores em Educação a Distância, 2014, São Carlos - SP. Anais do II SIED:EnPEd 2014. 